\title{
Peer Review of "The Exchange of Informational Support in Online Health Communities at the Onset of the COVID-19 Pandemic: Content Analysis"
}

\author{
Anonymous

\section{Related Articles:} \\ Preprint: https://preprints.jmir.org/preprint/27485 \\ Authors' Response to Peer-Review Reports: https://med.jmirx.org/2021/3/e31329/ \\ Published Article: https://med.jmirx.org/2021/3/e27485/
}

(JMIRx Med 2021;2(3):e31416) doi: 10.2196/31416

\section{KEYWORDS}

COVID-19; health information; informational support; online health; online health communities; online platform; pandemic; social support

This is a peer-review report submitted for the paper "The Exchange of Informational Support in Online Health Communities at the Onset of the COVID-19 Pandemic: Content Analysis".

\section{Round 1 Review}

\section{General Comments}

My comments are as follows:

1. The authors [1] did not review relevant existing works carefully. A number of studies on online health communities
(OHCs) have been conducted already. You should compare your results with these relevant works.

2. Although you have mentioned that one coder is a limitation, it is an evitable limitation and needs to be overcome, or how can you ensure the accuracy of the results? I suggest that the authors recode the posts and responses by two coders (at least) who are familiar with this field.

3. What are the criteria by which you determine the name of the coding and the definition of the coding?

\section{Conflicts of Interest}

None declared.

\section{Reference}

1. Jong W, Liang OS, Yang CC. The Exchange of Informational Support in Online Health Communities at the Onset of the COVID-19 Pandemic: Content Analysis. JMIRx Med 2021 Jul 22;2(3):e27485 [FREE Full text] [doi: 10.2196/27485]

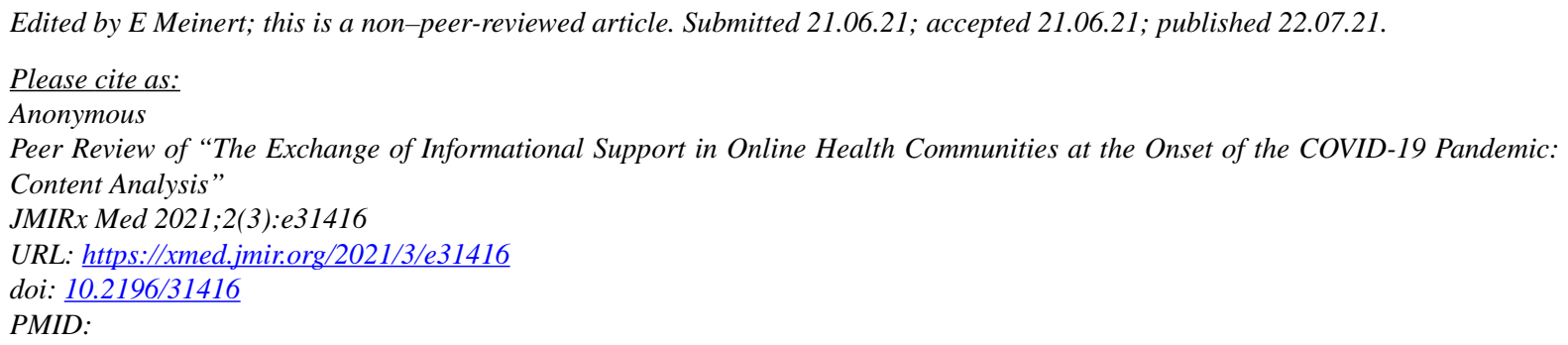

(C) . Originally published in JMIRx Med (https://med.jmirx.org), 22.07.2021. This is an open-access article distributed under the terms of the Creative Commons Attribution License (https://creativecommons.org/licenses/by/4.0/), which permits unrestricted use, distribution, and reproduction in any medium, provided the original work, first published in JMIRx Med, is properly cited. 


\section{JMIRx Med}

The complete bibliographic information, a link to the original publication on https://med.jmirx.org/, as well as this copyright and license information must be included. 